\title{
Type 2 Respiratory Insufficiency, Pulmonary Hypertension, and Obstructive Sleep Apnea Syndrome that Developed in Morquio Syndrome
}

\author{
Pınar Yıldız Gülhan, Aydanur Ekici, Mehmet Ekici, Dilay Çimen
}

Department of Chest Diseases, Kurlkkale University Faculty of Medicine, Kurlkkale

\begin{abstract}
Mucopolysaccharidosis type IVA (Morquio syndrome) is a multisystemic autosomal recessive transitive disease induced by an N-acetylgalactosamine 6 sulfatase (GALNS) gene defect, progressing with lysosomal stock failure. The accumulation of chondroitin 6 sulfate and keratin sulfate is observed in the tissues due to GALNS deficiency. We presented a case in which Morquio syndrome was successfully treated with noninvasive mechanical ventilation in accordance with the literature. The case had obstructive sleep apnea syndrome (OSAS) induced by an obstruction that emerged as a result of type 2 respiratory insufficiency resulting from throcal deformity, inspiratory muscle weakness, pulmonary hypertension, and the accumulation of diffuse mucopolysaccharide in the upper respiratory tract.
\end{abstract}

Keywords: Morquio syndrome, respiratory insufficiency, sleep apnea

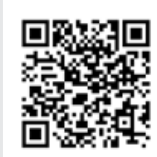

Received Date: 03.03.2012

Accepted Date: 07.07.2012

Available Online Date: 02.12.2014

Address for correspondence

Pinar Ylldız Gülhan, Department of Chest Diseases, Krrkkale University Faculty of Medicine, Krrkkale, Turkey

E-mail: pinaryildiz691@hotmail.com

(C) Copyright 2014 Turkish Respiratory Society (TRS) Eurasian J Pulmonol 2014

DOI: 10.5152/ejp.2014.85579

- Available online at www.eurasianjpulmonol.com

\section{INTRODUCTION}

Mucopolysaccharidosis type IVA (Morquio syndrome) is a multisystemic autosomal recessive transitive disease induced by an N-acetylgalactosamine 6 sulfatase (GALNS) gene defect, progressing with lysosomal stock failure. In Morquio syndrome, the accumulation of chondroitin 6 sulfate and keratin sulfate is observed in the tissues due to GALNS deficiency. $\mathrm{N}$-acetyl galactosamine 6 sulfatase is an enzyme required for the removal of keratin and chondroitin 6 sulfate. Symptoms arise due to the accumulation of these substrates, which can not be regressed in lysosomes. The major clinical symptom is skeletal system involvement (1). The defective enzyme GALNS in the classic mucopolysaccharidosis IV syndrome (MPS IV type A) was found in 1974. Two years later, another defective enzyme, $\beta$-galactosidase, showing normal sulfatase activity but causing clinical characteristics of MPS IV, was discovered, and this form of the disease was described as type B. Type A is the severe form the disease, and type B is the mild form (2). In addition to the disease, short stature, spinal deformities, odontoid hypoplasia, corneal opacity, cardiac anomalies, hepatosplenomegaly, hearing problems, and dental anomalies are observed $(3,4)$. The respiratory problems observed in Morquio syndrome contain restrictive-type respiratory failures caused by thoracic deformities and respiratory muscle weakness. Another reason for the respiratory problems in these patients is obstructive sleep apnea syndrome (OSAS) (4-6).

\section{CASE PRESENTATION}

A 20-year-old female patient complaining of non-exertional and progressive dyspnea that had started 1 week ago was admitted due to an anamnesis of severe dyspnea. After an enzyme defect had been detected and a diagnosis of Morquio syndrome had been made due to snoring and witnessed apnea symptoms when the patient had been 3 years old, OSAS had been considered, and in 1999, the patient had undergone tonsillectomy-adenomectomy surgery. After the operation, the patient's snoring and witnessed apnea had been fully recovered, but in the last 2 years, her complaints reappeared.

The physical examination revealed that the general condition of the patient was moderate, and the respiratory rate was $32 / \mathrm{min}$. In the inspection, in accordance with Morquio syndrome, short stature 


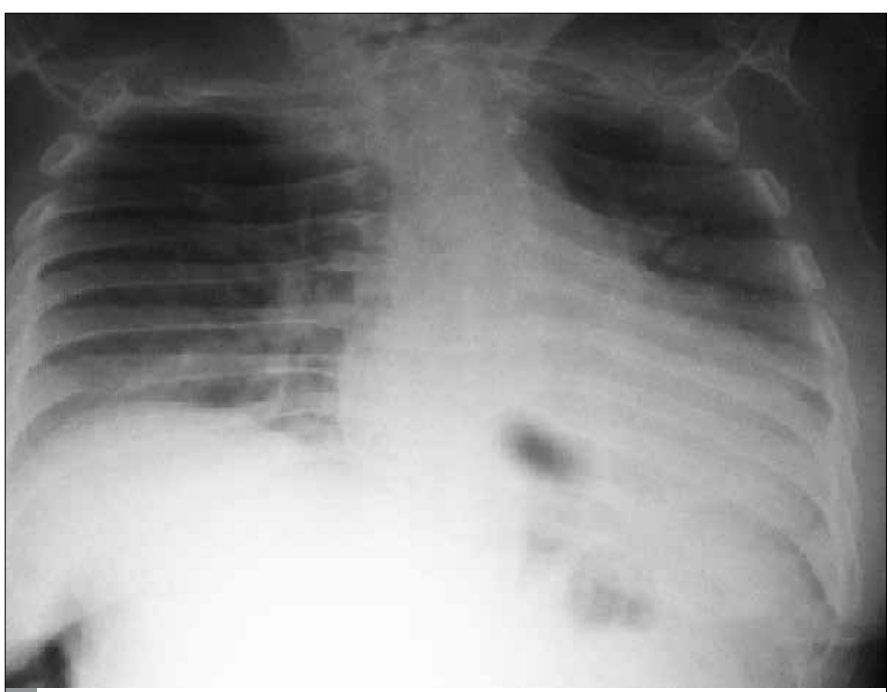

Figure 1. In posteroanterior chest radiography, decreased volume of the lungs and narrowed intercostal spaces.

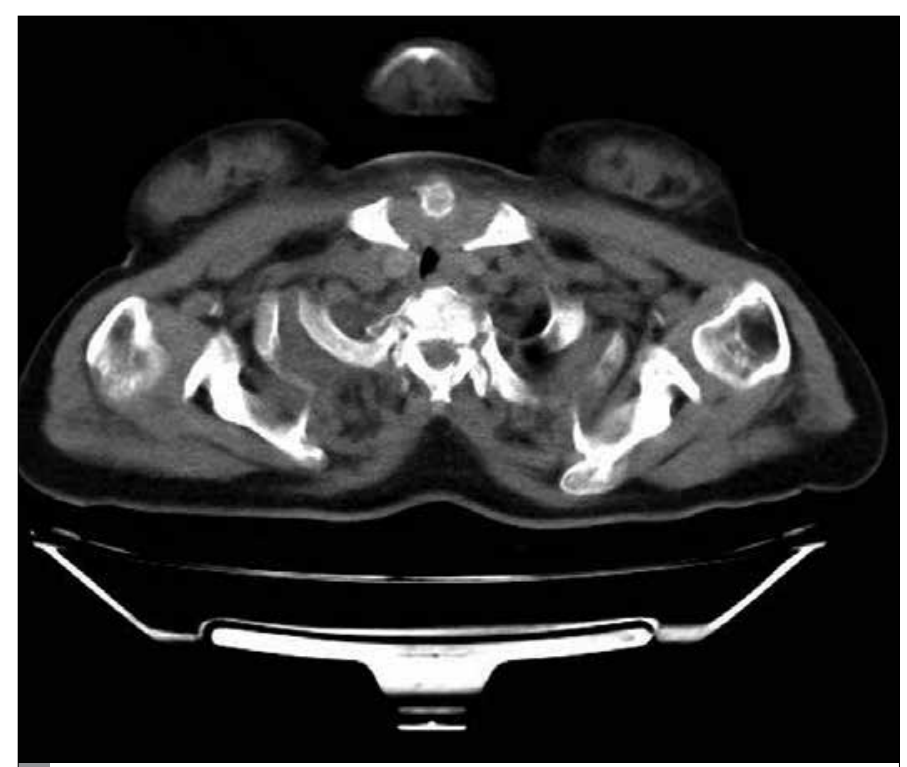

Figure 2. In the computed tomography of thorax, tracheal lumen contraction.

(94 cm), short neck, and kyphoscoliosis (thoracolumbar kyphosis and left thoracic scoliosis) were present. The body weight of the patient was measured as $23 \mathrm{~kg}$. The mucosa was cyanotic in appearance. In the ear-nose-throat examination, in the tongue base, posterior pharyngeal wall, lateral pharyngeal wall, epiglottis, and vocal cords, an appearance thought to be related to the abnormal accumulation of mucopolysaccharides was observed. The body temperature of the case was normal $\left(36.5^{\circ} \mathrm{C}\right)$. Blood pressure was $110 / 60 \mathrm{~mm} \mathrm{Hg}$, and pulse was $70 / \mathrm{min}$. Respiratory sounds were normal in auscultation. In the patient's arterial blood gas analysis, $\mathrm{pH}: 7.35, \mathrm{PaO}_{2}: 40 \mathrm{~mm} \mathrm{Hg}$, $\mathrm{PaCO}_{2}: 60 \mathrm{~mm} \mathrm{Hg}, \mathrm{SO}_{2}: 71.5 \% \mathrm{HCO}_{3}: 34.7 \mathrm{mmoL} / \mathrm{L}$, and hypercapnia and hypoxemia were present. Posteroanterior chest radiography revealed that the volume of the lungs was decreased and the intercostal spaces were narrowed, but there was no parenchymal infiltration (Figure 1). The computed tomography of the thorax and neck also showed tracheal lumen contraction at the level of the thyroid gland
(Figure 2). Mediastinal structures were moved to the left, and there was a decrease in the left lung volume. Areas of atelectasis showing transparenchymal extension in the right upper anterior lobe, lateral segment of the middle lobe, and left lower lobe laterobasal segment were observed (Figure 3).

In the transcutaneous echocardiography, the systolic pulmonary artery pressure based on the tricuspid valve insufficiency was 80 $\mathrm{mm} \mathrm{Hg}$, and the mean pulmonary artery pressure was measured as $54 \mathrm{~mm} \mathrm{Hg}$. The patient, with right ventricular papillary muscle hypertrophy and right ventricular hypertrophy, the diastolic gradient between the pulmonary artery and the right ventricle was $38 \mathrm{~mm}$ $\mathrm{Hg}$, and she had first-degree tricuspid valve insufficiency. Pulmonary function tests could not be performed, since the patient was not cooperative with the procedure.

With these findings, the patient was admitted to our clinic with a provisional diagnosis of type 2 respiratory failure, pulmonary hypertension, and OSAS. The patient's treatment started with nasal 2-3 L/min oxygen and bilevel positive airway pressure (BPAP) with $8 \mathrm{~cm} \mathrm{H}_{2} \mathrm{O}$ inspiratory positive airway pressure (IPAP), $5 \mathrm{~cm} \mathrm{H}_{2} \mathrm{O}$ expiratory positive airway pressure (EPAP). Daily ABG controls and BPAP pressures were gradually increased. Due to $\mathrm{CO}_{2}$ retention, the patient was given a diet that was poor in carbohydrates and rich in lipid, and nutrition solutions were added accordingly. The case, who was considered to have respiratory muscle weakness, was given puckered lip, diaphragm muscle strengthening, and postural exercises, and we had her perform those exercises regularly 4 times a day, for 15 minutes. The patient's arterial oxygen saturation, monitored during the exercises, was observed to be high. BPAP pressures were increased up to IPAP: $18 \mathrm{~cm} \mathrm{H}$ O and EPAP: $6 \mathrm{~cm}$ $\mathrm{H}_{2} \mathrm{O}$ pressure. The case was discharged after being informed that she should use an oxygen concentrator and a BPAP device. After being discharged, the patient's ABG analysis in room air without BPAP showed $\mathrm{pH}: 7.35, \mathrm{PaCO}_{2} 46 \mathrm{~mm} \mathrm{Hg}, \mathrm{PO}_{2}: 41 \mathrm{~mm} \mathrm{Hg}$, and $\mathrm{SO}_{2}: 73.4 \%$. Two weeks after her discharge, in her stable period, the case was given polysomnography (PSG) under 1-2 liters/min oxygen treatment. With polysomnography, the apnea-hypopnea index was 28.8, apnea index was 21.6, desaturation index was 11 , arousal index was 17.1 , minimal $\mathrm{O}_{2}$ saturation was $84 \%$, and average overnight oxygen saturation was $89 \%$. Her total sleep time was 2 hours, and sleep quality was $85 \%$. With these findings, the case was diagnosed with moderate OSAS. Two years later, a control PSG accompanied with BPAP was performed on the case, who visited the clinic for checkups and used the oxygen concentrator and BPAP device regularly. According to the control PSG results: apnea-hypopnea index: 3.4, apnea index: 1, and hypopnea index: 5 . Total sleep time was 3 hours, and sleep efficiency was $53.5 \%$, and our patient did not desaturate during her sleep.

Since the patient was unable to walk due to skeletal involvement as a result of neurological disabilities, the 6-minute walk test could not be performed, and right heart catheterization-vasoreactivity testing could not be performed because of the current posture. The patient was started on inhaled iloprost treatment with a diagnosis of secondary pulmonary hypertension. Following 14-month inhaled iloprost therapy, her echocardiography results showed that the systolic pulmonary artery pressure, which was calculated on tricuspid valve regurgitation, decreased to $60 \mathrm{~mm} \mathrm{Hg}$, and the $A B G$ results were $\mathrm{pH}$ : 7.36, $\mathrm{PaCO}_{2}: 52 \mathrm{~mm} \mathrm{Hg}, \mathrm{PO}_{2}: 77 \mathrm{~mm} \mathrm{Hg}$, and $\mathrm{SO}_{2}$ : 94\%. The patient is still receiving inhaled iloprost, BPAP (IPAP: $14 \mathrm{~cm} \mathrm{H2O,} \mathrm{EPAP:} 6 \mathrm{~cm}$ $\mathrm{H} 2 \mathrm{O}$ ), and long-term oxygen therapy and is having regular checkups. 


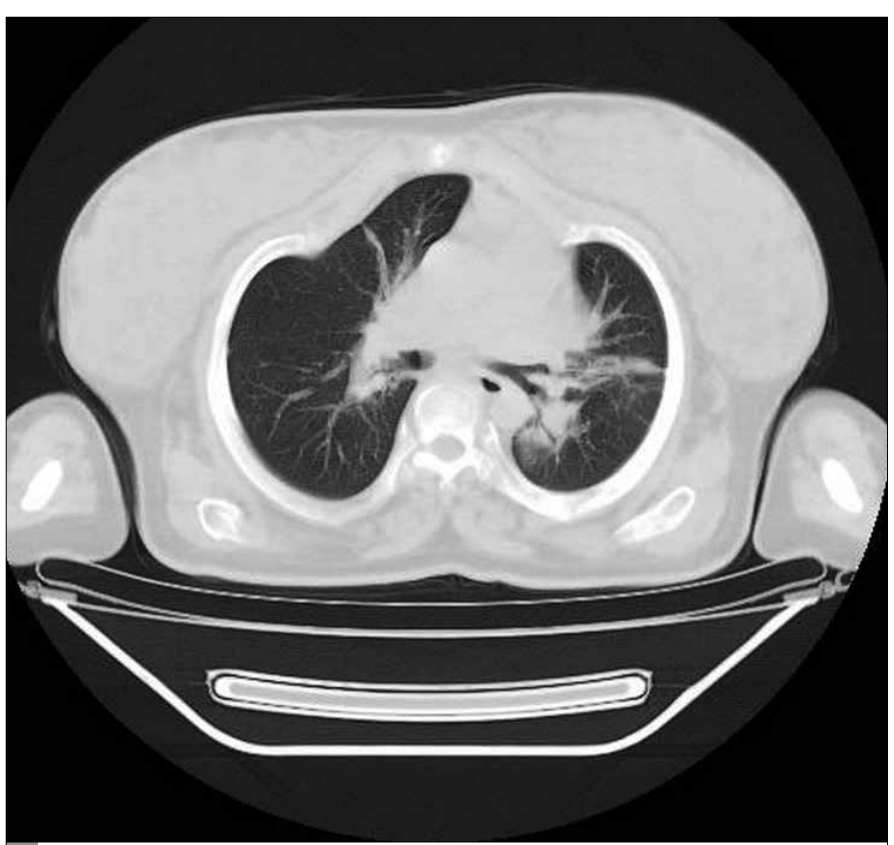

Figure 3. In the parenchymal window computed tomography of the thorax, areas of atelectasis showing transparenchymal extension in the left lung.

\section{DISCUSSION}

Mucopolysaccharidosis type IVA (Morquio syndrome) is a multisystemic autosomal recessive, transitive, lysosomal stock failure disease with a GALNS gene defect. Due to the defect in the gene that is necessary for the catabolism of keratin and chondroitin, accumulation of keratin and chondroitin 6 sulfate occurs in lysosomes, and as a result of this accumulation, symptoms appear. The major clinical symptom is skeletal system involvement (1). Short stature, spinal deformities, odontoid hypoplasia, corneal opacity, cardiac anomalies, hepatosplenomegaly, hearing problems, and dental anomalies are observed, but mental retardation is not seen $(3,4)$. Death usually occurs due to neurological deficits caused by respiratory failure and vertebral anomalies (3).

Respiratory failures in these patients are caused by nasopharyngeal obstruction, thoracic deformities, and ventilation/perfusion disorders. In the supine position, nasopharyngeal obstruction, obstruction, and hypoxemia might develop, depending on macroglossia. Obstruction induced by tonsil and adenoid hypertrophy causes hypoventilation and deepening hypoxemia and apneic episodes during sleep (3). Our case was operated on in 1999 due to tonsil and adenoid hypertrophy. Although the patient's snoring and witnessed apnea had fully recovered after the surgery, these symptoms reappeared in the last 2 years.

In cases with Morquio syndrome, restrictive-type respiratory failure might develop due to chest wall deformities. In these cases, hypoxic and hypercapnic (type 2 ) respiratory failure and respiratory muscle weakness may occur. Savcl et al. (6) reported that respiratory muscle weakness in patients with Morquio syndrome is caused by metabolic abnormalities, wall deformities, and the muscles' not being used. In our case, hypoxemia and hypercapnia caused by kyphoscoliosis, pectus carinatum deformity, and respiratory muscle weakness were also present. Due to respiratory muscle weakness, regular breathing exercises while the patient was monitored (puckered lip, diaphragm muscle strengthening, and postural exercises) were performed, and during these exercises, a rise of arterial oxygen saturation from $60 \%$ to $90 \%$ was observed. This proved that the hypoxemia was caused by the respiratory muscles not being used. In these cases, hypoxemia may result from right-left shunts due to microatelectasis caused by chest wall restriction (7). Thorax CT revealed atelectasis in both lungs, and this situation made us think that it might be one of the causes of the hypoxemia.

In these patients, OSAS might develop as a result of upper respiratory tract obstruction due to recurrent accumulation of mucopolysaccharides. These pathological findings may reoccur, even after surgical procedures are performed, because of obstruction in the upper respiratory tract. Therefore, patients must be followed in terms of OSAS. Furthermore, thoracic deformity and respiratory failure due to the widespread accumulation of mucopolysaccharides may develop in these patients.

\section{CONCLUSION}

Through OSAS and respiratory failure treatment, it is possible to prolong these patients' lives. In our case, after the treatment, it was also observed that hypercapnia was improved, OSAS symptoms disappeared, and the apnea-hypopnea index fell by as much as 3.4.

Informed Consent: Written informed consent was obtained from patient who participated in this study.

Peer-review: Externally peer-reviewed.

Author Contributions: Concept - P.Y.G., A.E., M.E., D.Ç.; Design - P.Y.G., A.E.; Supervision - P.Y.G., A.E., M.E.; Funding - P.Y.G.; Materials - P.Y.G., A.E., M.E., D.Ç.; Data Collection and/or Processing - P.Y.G., A.E., M.E.; Analysis and/or Interpretation - P.Y.G., A.E., M.E., D.Ç.; Literature Review - P.Y.G., A.E.; Writer - P.Y.G., M.E.; Critical Review - P.Y.G., A.E., M.E., D.Ç.

Conflict of Interest: No conflict of interest was declared by the authors.

Financial Disclosure: The authors declared that this study has received no financial support.

\section{REFERENCES}

1. Bouzidi H, Khedhiri S, Laradi S, Ferchichi S, Daudon M, Miled A. Mucopolysaccharidosis IVA (Morquio A syndrome): clinical, biological and therapeutic aspects. Ann Biol Clin (Paris) 2007; 65: 5-11.

2. Can C, Polat S, Bayazıt I, Yasar M, Altıntas A. Systemic and Ophthalmological Findings of a Patient with Morquio's Syndrome: Case Report. Türkiye Klinikleri Ophthalmol 2011; 20: 31-4.

3. Hope EO, Farebrother MJ, Bainbridge D. Some aspects of respiratory function in three siblings with Morquio-Brailsford disease. Thorax 1969; 28: 335-41. [CrossRef]

4. Walker PP, Rose E, Williams JG. Upper airways abnormalities and tracheal problems in Morquio's disease. Thorax 2003; 58: 458-9. [CrossRef]

5. Yagmurdur $\mathrm{H}$, Cingilli $\mathrm{C}$, Basar $\mathrm{H}$. Anesthesia applications in children with mukopolysacharidosis type II (hunter syndrome) and conjenital hypothyroidism. Türk Anest Rean Der Dergisi 2007; 35: 68-71.

6. Savci S, Ozturk M, Inal D, Gultekin Z, Arikan H, Kalkanoglu Sivri H. Inspiratory muscle training in morquio's syndrome. Pediatr Pulmonol 2006; 41: 1250-3. [CrossRef]

7. Buhain WJ, Rammohan G, Berger HW. Pulmonary function in morquio's disease: a study of two siblings. Chest 1975; 68: 41-5. [CrossRef] 